\title{
A 2200-Year Old Inquiry-Based, Hands-On Experiment in Today's Science Classrooms
}

\author{
S. Sotiriou ${ }^{1} \&$ F. X. Bogner, ${ }^{2, *}$ \\ ${ }^{1}$ Ellinogermaniki Agogi, R\&D Department, Pallini, Athens, Greece \\ ${ }^{2}$ Centre of Math and Science Education (Z-MNU), University of Bayreuth, D-95447 Bayreuth, Germany \\ *Corresponding author: Centre of Math and Science Education (Z-MNU), University of Bayreuth, Univ. Campus, \\ D-95447 Bayreuth, Germany. E-mail: franz.Bogner@uni-bayreuth.de
}

The study was funded by OpenScienceResources (OSR), a European initiative with 20 institutions from 12 countries (ECP-2008-EDU-428045).

Received: February 26, 2015

Accepted: March 10, $2015 \quad$ Online Published: April 2, 2015

doi:10.5430/wje.v5n2p52

URL: http://dx.doi.org/10.5430/wje.v5n2p52

\begin{abstract}
The ancient Eratosthenes experiment concerning the earth's circumference offers the opportunity of an inquiry-based revival in today's science classrooms: A multinational European science education initiative (acronym: OSR) introduced this experiment as a hands-on basis to extract the required variables and to exchange results with classroom peers across two continents, including Finland in the North, via Poland and Serbia to Greece and Egypt in the South. The aims behind focused on typical science requirements in classroom approaches such as measurement spreads of scores, translation of one score into its context as well as to solve a complex scientific question with simple hands-on results when unveiling nature's hidden principles. Within the scope of this present study, 2180 students from 89 schools in 5 different countries (Finland, Poland, Serbia, Greece, Egypt) completed the Eratosthenes experiment on the same day. Working groups of up to four students collected the measurement scores within their school sites which by selection covered about 30 degrees of latitude. The analyses clearly show more accuracy in the scores as more distant the measurement sites are located (within Greece: 17.6\% error; Greece Finland: $1.3 \%$ error). Recommendations for school implementations as well as its potential in experimental science classrooms are discussed in detail.
\end{abstract}

Keywords: Eratosthenes experiment; hands-on learning; cooperative learning; science education; measurement errors

\section{Introduction}

Inquiry- and problem-based implementations in science education are frequent claims that promise to overcome well-known constraints in science classrooms (e.g. Rocard, Csermely, Jorde, Lenzen, Walberg-Henriksson, \& Hemmo, 2007). As a central component of science learning inquiry is regarded as essential for a student's learning process due to its need to ask and refine questions, to find solutions to real problems, to design and conduct explorations, to gather information, to analyze and calculate individually collected data, to make interpretations, to draw and defend conclusions and to appropriately report findings either to peers or to teachers (e.g. Novak \& Gowin, 1984; Roth \& Roychoudhury, 1993; Coleman 1998). Therefore, inquiry-based learning is repeatedly claimed to ensure better learning levels, since a thorough understanding is needed to individually isolate a learning issue rather than to simply repeat factual contents and simple information details (e.g., Bybee, 2000; Blanchard, Southerland, Osborne, Sampson, Annetta, \& Granger, 2010). To set a pathway toward learning science by inquiry, to support the adoption of inquiry-learning by reducing individual constraints and to apply appropriate methods as well as to label exemplarily best practice cases are the main aims within inquiry-based science education; just remembering simple facts or being told about science no longer fits the requirement of modern societies (Sotiriou \& Bogner, 2005; Alberts, 2009). Hereby, the approach potential is widespread from using open inquiry until guided inquiry. If inquiry 
is to be more that obtaining expected results, students need freed up in order to ask and research their own questions. In science education experiments, very often it is helpful to pursue a teacher-directed, not student-directed inquiry (Martin-Hansen, 2002). Within this view, students are being brought into subjection to science, not conversation with it, they are being prepared to develop informed opinions, to become convinced of current scientific ways of explaining the world (Bozic \& Ducloy, 2008; Ireland, Watters, Lupton, \& Lunn, 2014). Consequently, preference is given to guided- rather than to open-inquiry (NRC 2000).

Students need to follow a learning vision to act like a scientist when answering a science question. In combination with traditional learning experiences students may use everyday technology such as google maps from the worldwide web. This approach requires scientific knowledge and knowledge about the nature of science and its methods as well in order to conclude to needed results (Decamp \& deHosson, 2012; Dutka, 1993). Quantitative studies with the intent of empirically monitoring efficacies of inquiry-based instructions clearly show advantages for inquiry-based approaches when potential disadvantages are avoided (e.g., Blanchard et al. 2010): Of course, there are limitations, for instance, the lack of guidance is often not welcomed by students who in general are accustomed to guided instructions in conventional classrooms (Kirschner Sweller, \& Clark, 2006). Although a minimum of guidance is often welcomed by academic educators, empirical studies, however, too often report strong evidence about lower effectiveness levels and less efficiency when open inquiry-based instruction is applied (e.g., Dean \& Kuhn 2007). In order to allow instruction with less guidance to develop its genuine superiority, more is needed than just its application in classrooms; specific preparation is needed to accumulate sufficient skills to succeed (Kirschner, et al.2006). As a major additional limitation, besides others, cognitive load always comes into play when unfamiliar learning environments block learning outcomes (Paas, Renkl, \& Sweller, 2004; Sweller, 1988; Scharfenberg \& Bogner, 2010, 2013).

Within the variety of approaches to teaching science, the ancient Eratosthenes experiment offers an ideal example from a triple point of view: (i) to follow an inquiry-based approach to solving discrepancies in data scores (Eratosthenes had read about empirical observations which he could not confirm), (ii) to generate simple a hands-on experiment to further understanding of the earth's shape and circumference which has been fiercely disputed over centuries as well as (iii) to exchange results within online repositories and thus enlarge the opportunities to cooperatively solve a scientific problem. Eratosthenes (ca. 276-194 B.C.) supposedly was the first person to precisely calculate the circumference of the earth. His interest in the issue began with reading a description that did not match his own conceptions that, on June $21^{\text {st }}$, the sun's rays convertically reach the bottom of a deep well without producing a shadow. This phenomenon was not observable in Alexandria, situated exactly $821 \mathrm{~km}$ north of the imaginary line (which nowadays is labeled the Tropic of Cancer) where the sun reaches the $90^{\circ}$ zenith. His measures were remarkably accurate by applying a simple model using distance and a pre-selected time. Surprisingly, Eratosthenes just needed to compare results obtained at the summer solstice at two sites. While at the Northern Tropic, the sun appeared directly above the zenith (providing no shadows), the situation in Alexandria was slightly different: In his conclusion, when measuring the sun's angle at both sites, [rewrite the remainder of the sentence:] he came to an arc of about 1/50th of a circle and finally corroborated a circumference of $39,690 \mathrm{~km}$. This measure came surprisingly close to the actual equatorial circumference of $40,075 \mathrm{~km}$ (with an error of just $4.2 \%$ ). This astonishing accuracy was mainly due to the expert bematists ("pace counter") who were trained to guarantee precise distance calculations. Even 17 centuries later, Christopher Columbus (1451-1506) followed much less accurate assumptions: Although he knew about Eratosthenes' conclusion, he mistrusted its accuracy and dramatically reduced the distances, leading to his conclusion that India is located few thousand miles west of Europe (thus labeling his discovery India and its inhabitants Indians).

The use of networking platforms is becoming increasingly popular in science classrooms. Science education in formal and informal contexts uses the potential of digital repositories to enrich conventional hands-on initiatives (Sotiriou \& Bogner 2011; Gialouri, Uzunoglou, Gargalakos, Sotiriou, \& Bogner, 2011). There is an impressive number of high quality repositories, which however often remains unexploited due to barriers such as the lack of interoperability standards between repositories, the inefficiency of content organization as well as metadata structures and the language barriers in Europe. The OpenScienceResources (OSR) initiative focused on formal and informal sets of "proof-of-concept" experiments in order to implement hands-on science education issues in the context of real-life situations; it is intended to promote effective widespread usage of problem-based science issues in classrooms (e.g., see initiatives such as OpenScienceResources [OSR], OpenDiscoverySpace [ODS], InspiringScienceEducation [ISE]). A major aim of the OSR initiative is the sharing of a repository of scientific digital objects in order to support its coherent use within the context of formal and informal learning situations (Van Joolingen, de Jong, Lazonder, Savelsbergh, \& Manlove, 2005; Sampson, Zervas, \& Sotiriou, 2011). 
The objectives of our study were five-fold: a) to define the exact time slot for the local noon; b) to measure the shadow during the local noon; c) to analyze the distance between school sites; d) to analyze the angular distance between them; and finally e) to monitor whether students can use an online forum to discuss why longer distances between two schools can get less measurement errors.

\section{Methods \& Procedures}

In the following, we describe, besides the original experiment, the detailed hands-on experiment for application in schools and the student sample that completed the experiment.

Original experiment: Eratosthenes knew about a site where at noon on a certain day the sun was directly overhead and he compared the situation with another site where this was not the case. Additionally he found measures of the distance between both sites which gave him the tool to proceed with his calculations. Although Eratosthenes' original experiment contained a number of serious errors, inaccuracies and guesses, he came close to the "correct" or "current" answer: For instance, the city of Syene is not located at the Tropic of Cancer but about 22 miles north; additionally, the city's location was not exactly south of Alexandria. Nevertheless, his writings have been lost anyway, but fortunately his experiment is still known through other writers of his era. The experiment ideally suits science education because of its simplicity, accuracy and it mathematical combination potential. Students can conceptualize space through measurement.

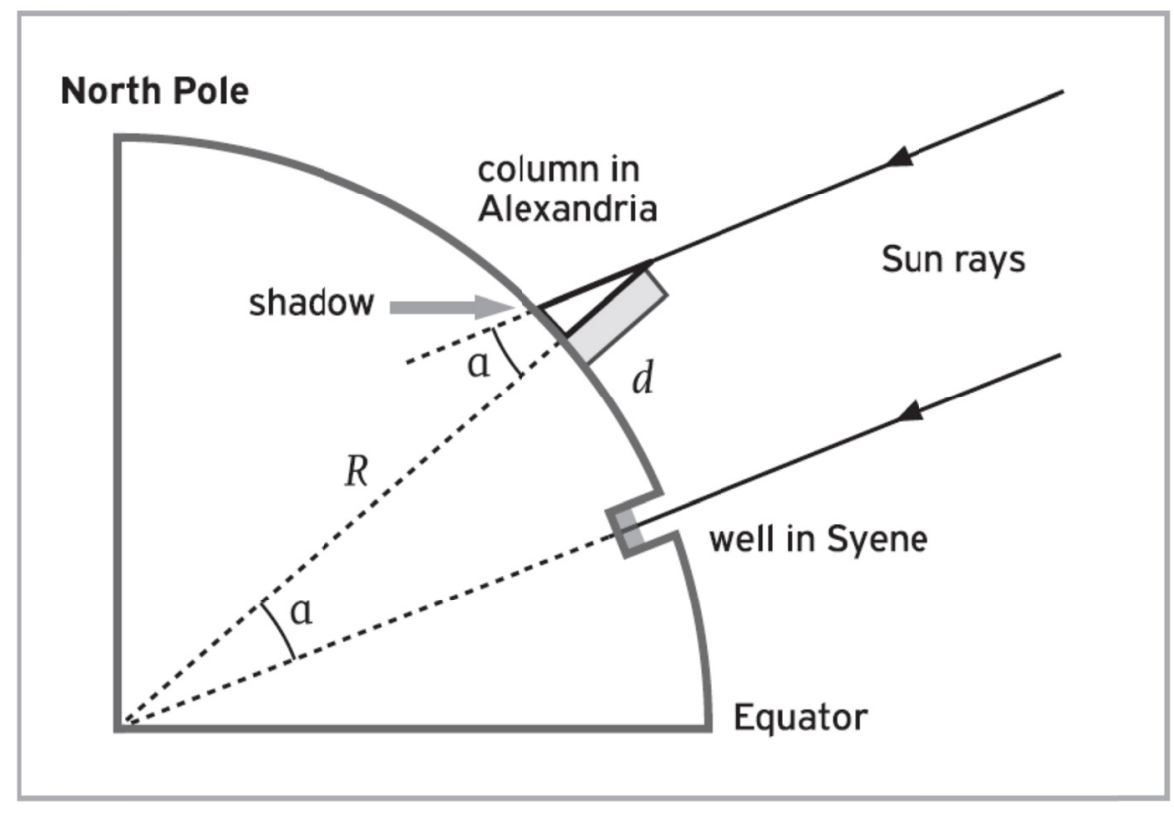

Figure 1. Pattern of the Original Eratosthenes Setting in Egypt to Define the Shadow Angles of Two Different Geographical Sites

Secondary school experiment: Eratosthenes succeeded in measuring the earth's circumference since the site of his investigation was located close to the Tropic of Cancer with the sun vertical at the summer solstice. Nevertheless, the experiment is not limited to specific sites on the earth, it can easily duplicated everywhere else (for instance, at every school site). Students complete individual shadow measurements in their school yards and share their results with a class from a school at another location, even quite far away. The schools have to take measurements at the local noon. Taking into account that students will measure the shadow of a $1 \mathrm{~m}$ long stick which may produce a small error of few centimeters, we need to select schools located at distances over $1000 \mathrm{~km}$ that will allow for a clear difference in the shadow observation of more than $10 \mathrm{~cm}$. Measurements at both locations need to be made when the sun reaches its zenith and the length of the shadow is at its minimum. On the 26th of March, within the Open Discovery Space school network activities, the Eratosthenes experiment was completed for numerous schools all over Europe. At first, the local noon needed to be determined, the moment when the sun reached the zenith and produced its minimum shadow. This shadow is falling north in the northern hemisphere where all our activities were performed. There are 
two ways to calculate the time of the local noon: Following the traditional approach, a stick is placed vertically on the ground (using a plumb line or a carpenter's level). At noon (12.00-13.00 CET), the shadow's length needs repeated measurement at short time intervals (e.g. every 5 minutes). The shadow will shorten as noon approaches, and then grow longer again once noon has passed. The shortest shadow length will be used in our calculations. An alternative (modern) approach is to use a web application such as www.stellarium.org (a digital planetarium), where each teacher beforehand defines the accurate time slot when sun reaches its zenith; this exact time slot sets the time for completing the experiment (see appendix). Altogether, all procedures contribute to the human issue of precise measuring, where a seemingly negligible deviation in a short shadow determination may multiply to a vast deviation when calculating the earth circumference. Therefore, our experiment isn't just a mathematical investigation, it is a scientific one.
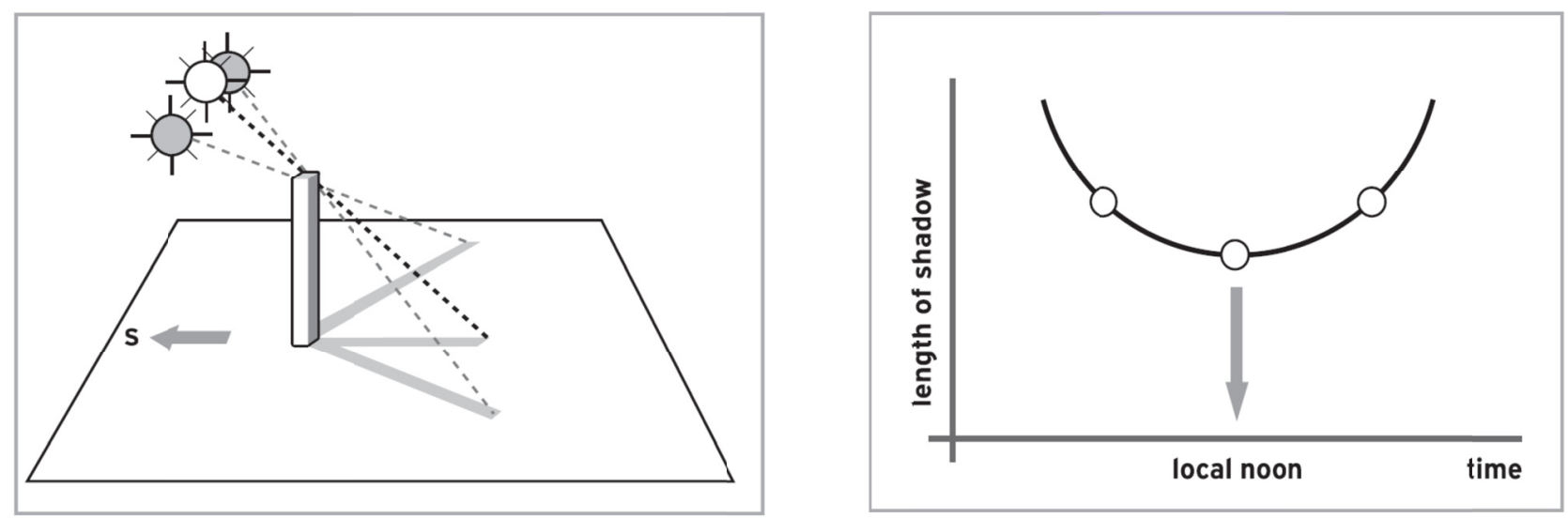

Figure 2. A: Students Complete a Series of Measurements in Order to Find the Time that the Shadow of the Stick is Shortest. This time is called local noon. B: The exact time can also be calculated by using Stellarium, a virtual planetarium. (Note: the figure presents the case for the Northern hemisphere).

Our sample consisted of 2180 students from 89 schools in 5 countries (Egypt: 355 students, 35 schools / Finland: 302 students, 6 schools / Greece: 685 students, 16 schools / Poland: 456 students, 22 schools / Serbia: 382 students, 10 schools). Age ranged from 10 to 16 years. In general, the experiment was completed within science lessons.

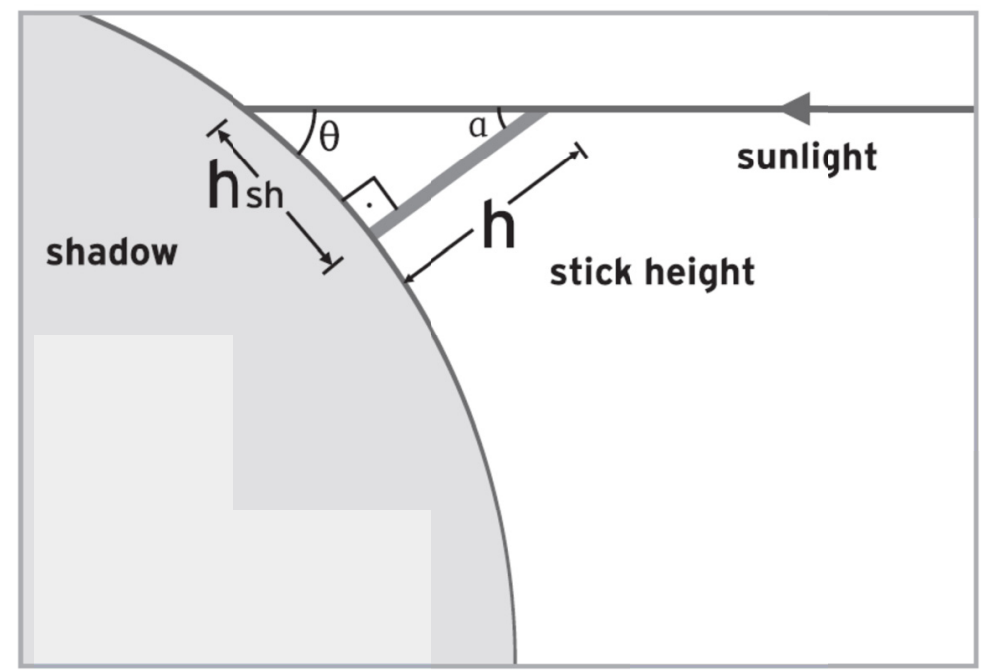

Figure 3. The Angle between the Vertical Stick and the Sunlight Can Be Calculated When the Length of the Stick and the Length of Its Shadow Are Known 
Shadow measurement on site. Students from all participating schools performed the experiment on one day. Students were separated into small teams, yielding numerous measurements at the same time. They checked the length of the stick $(1 \mathrm{~m})$, placed it into the sunlight and measured at the given time the length of the stick's shadow: Therefore, the stick, the stick's shadow and the line that connects the upper part of the stick and the end of the shadow (sunlight direction) form a right triangle. Subsequently, students calculated the angle: a (as shown in Figure 3), the angle between the vertical stick and the sun. This angle is also equal to the angular distance between the location the experiment was performed and the place where the sunlight is perpendicular to the surface of earth, when the sun is directly overhead.

Measuring the distance between two school locations. For measuring the distance between school locations, Google Earth application (http://www.google.com/earth/) was applied. We made sure that the distance between two collaborating schools was measured on the same meridian (Figure 4). The Open Discovery Space school network involves more than 1000 schools in Europe so this offers a opportunity to select schools that are on the same meridian and to establish twinning projects between them.

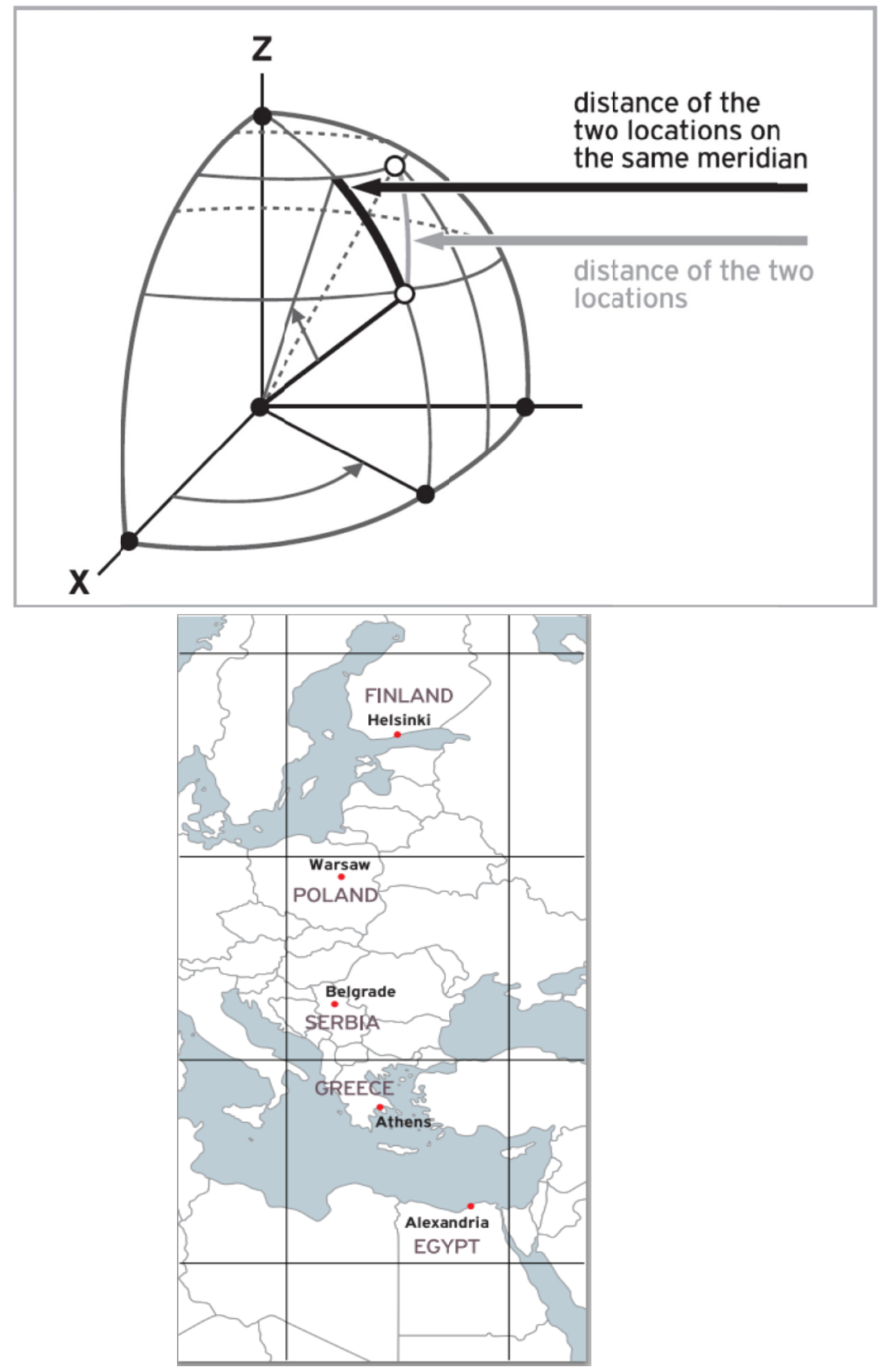

Figure 4. In Those Cases Where Collaborating Schools Are Not on the Same Meridian, Their "Distance" Measurement Must Be Adjusted By Projecting the Actual Distance onto the Same Meridian. This Can Be Done By Using the Google Earth Application.

Figure 5. The Large Open Discovery Space School Network Allows Teachers to Select Schools from Different Countries That Are Located in the Same Meridians And Perform Twinning Projects. Athens (Greece) and Helsinki (Finland) Are on the Same Meridian, So This Project Offers A Unique Opportunity for Completing the Eratosthenes Experiment. 


\section{Results}

\subsection{Measuring the Angle between Different School Locations}

Students from our collaborating schools defined the angles $\alpha_{1}$ and $\alpha_{2}$ and the distance between the two school locations, $\mathrm{D}_{21}$ (see methods). The angle between the two locations was calculated by subtracting the smaller angle (southern location) from the larger angle (northern location): $\alpha_{21}=\alpha_{2}-\alpha_{1}$. After each school had computed its average score loaded it onto the portal, the score was made public for the other participating schools.

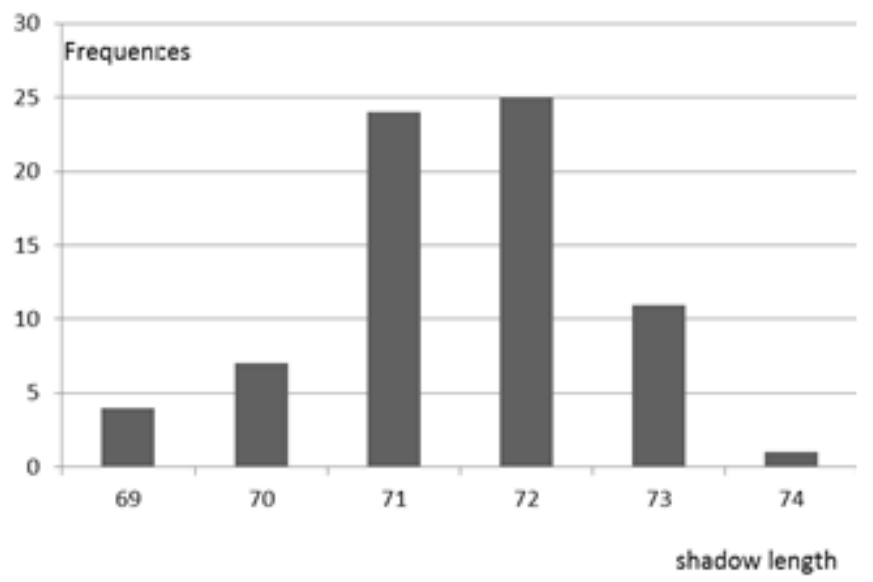

Figure 6. Data from One School (Ellinogermaniki Agogi, Greece) Where the Experiment Was Performed 72 Times The graph presents the measurements of the stick shadow and their frequencies. 72 measurements were completed by 210 students working in small groups, yielding on average $71.4 \mathrm{~cm}$ of shadow (see Table 1)

Table 1. Summarized Average Score of All Participating Schools in Greece

\begin{tabular}{lll}
\hline School Location in Greece & $\begin{array}{l}\text { Shadow Length } \\
\text { Average Value }\end{array}$ & - Angle $\alpha\left(^{\circ}\right)$ \\
\hline Athens/Pallini & 71,4 & 35,5 \\
Athens/Glyfada & 71,4 & 35,5 \\
Athens/Markopoulo & 71,2 & 35,5 \\
Athens/Lavrio & 71,2 & 35,5 \\
Athens/Pyrgos & 71 & 35,4 \\
Chios & 73 & 36,2 \\
Volos & 75 & 37,0 \\
Portaria & 76 & 37,2 \\
Corfu & 76,5 & 37,4 \\
Thessaloniki & 79 & 38,5 \\
Komotini & 79 & 38,5 \\
Herakleion & 65 & 33,1 \\
Chania & 66 & 33,3 \\
\hline
\end{tabular}

Table 2. Average Scores of Participating Schools in the 5 Countries

\begin{tabular}{llll}
\hline School Location & Country & Shadow Length $(\mathrm{cm})$ & Angle $\alpha\left(^{\circ}\right)$ \\
\hline Alexandria & Egypt & 55,4 & 29 \\
Athens/Pallini & Greece & 71,4 & 35,5 \\
Belgrade & Serbia & 92 & 42,6 \\
Warsaw & Poland & 119,1 & 50 \\
Vantaa & Finland & 160 & 58 \\
\hline
\end{tabular}




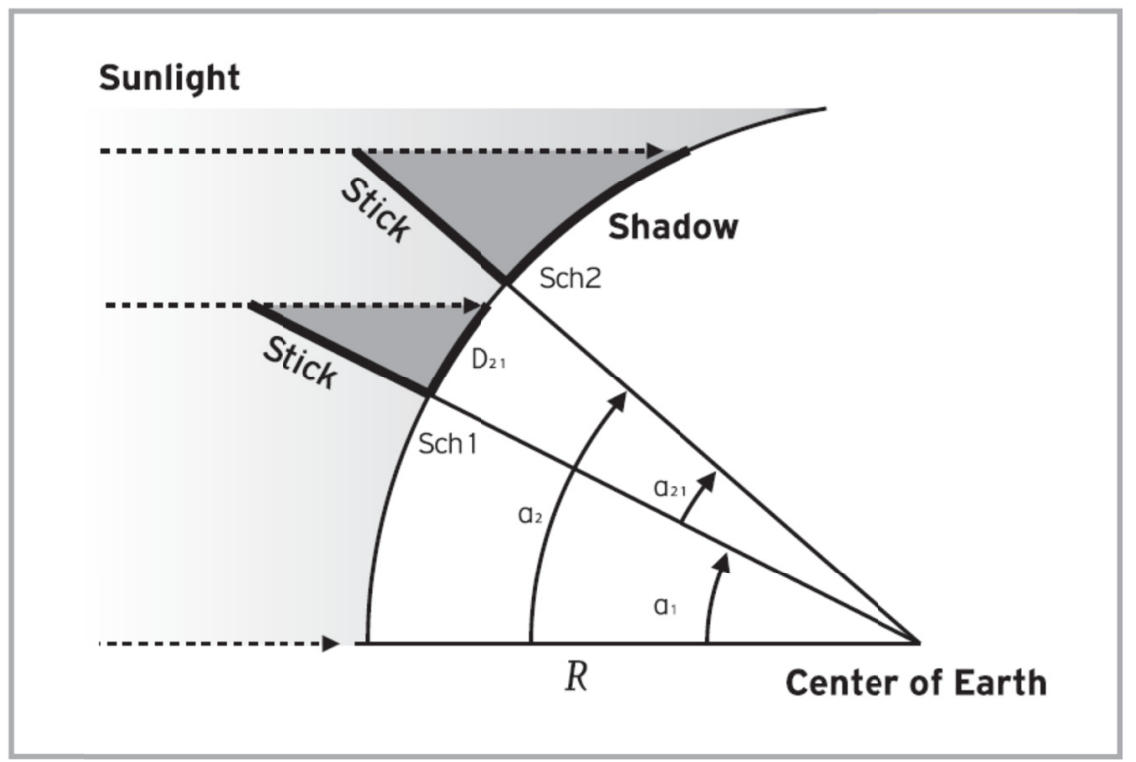

Figure 7. The Angle $\alpha_{12}$ Corresponds to the Arc $\left(\mathrm{S}_{\mathrm{ch} 1} \mathrm{~S}_{\mathrm{ch} 2}\right)$, Namely to the Distance $\mathrm{D}_{21}$ between the Locations of the Two Schools

\subsection{Calculating the Circumference}

The circumference was calculated with regard to an angle of $360^{\circ}$.

(Earth Circumference) $/ 360=\mathrm{D}_{21} / \alpha_{21}$. With the earth's circumference of $40075 \mathrm{~km}$, we can estimate the error in each of the measurements.

Table 3 presents the results for pairings combining the original experiment's scores: Pallini [Greece] - Thessaloniki [Greece], Pallini [Greece] - Warsaw [Poland], Pallini [Greece] - Alexandria [Egypt], Pallini [Greece] - Belgrade [Serbia] and Pallini [Greece] - Vantaa [Finland]

\begin{tabular}{llll}
\hline Twinning Schools & $\begin{array}{l}\text { Distance between the } \\
\text { Schools }(\mathrm{km})\end{array}$ & $\begin{array}{l}\text { Calculated Earth } \\
\text { Circumference }\end{array}$ & Error (\%) \\
\hline Pallini - Vantaa & 2470,4 & 39527 & 1,3 \\
Pallini - Warsaw & 1574,0 & 39078 & 2,5 \\
Pallini - Belgrade & 770,0 & 38500 & 3,9 \\
Pallini - Alexandria & 700,5 & 38181 & 4,7 \\
Pallini - T'Saloniki & 271,0 & 32520 & 17,6 \\
\hline
\end{tabular}

The error decreases as distances grow larger, as discussed in the methodology section. The wide network of schools offers the opportunity to undertake a variety of combinations and to involve more than two schools in the calculation process. Consequently, students needed to discuss with the teacher, (i) why individual measurements had to be made at a given time, (ii) why the time slots of measurements were not always simultaneous with their fellow students', (iii) why measurements needed to be compared with the real value of the Earth's circumference; and (iv) which sources of error may exist and why they were not taken into consideration.

\section{Discussion}

Inquiry-based hands-on experiments in classrooms require simple constructs to satisfy a student's curiosity. The ancient Eratosthenes experiment provides an excellent inquiry-based hands-on approach for today's students to conceptualize and solve an abstract problem that even contradicts everyday conceptions: We all know that the Earth is round although it appears flat (Vosniadou, 1994; see below). The Eratosthenes experiment fulfils many requirements of science lessons: Students need to check their individual measurement scores and to transform them into real world measures, and they need to transfer physical observations into mathematical values (Makowski \& 
Strong, 1996). The Eratosthenes experiment with its very simple approach requires all the subject integrative argumentation which brought Eratosthenes to his famous solution. No fancy equipment is needed, but simply to following the footsteps of Eratosthenes with his very simple assumptions may force a student to think and to argue as a scientist by discussing evidence (Lott, 1983; Brooks \& Brooks, 1999). Nevertheless, students aren't discussing why the circumference of the earth is important to know or whether they may improve their Eratosthenes measurement using the technologies, the lesson's question is focusing on why they are taking so many measurements when only two will do. Therefore, our approach may rather be an activity than an experiment, since the latter commonly is trying to answer a research question while the first is repeating an experiment with the intent to come as close as possible to an already known answer.

\subsection{Cooperation with Peers}

A crucial aspect guarantees the success of our experiment: The effective cooperation between different schools (in different countries) completing the same experiment on the same day and exchanging results with peers. Students realize the dependency on partner schools as a precondition to calculate their own estimation of the Earth's circumference. The proposed approach built upon school cooperation in context and offering unique opportunities to demonstrate the potential of inter-school international projects (at least in Europe, national cooperation does not yield sufficiently accurate results). The proposed approach brings school cooperation to a more advanced level (beyond usual school twinning projects) where students realize the importance of the timing of the measurements, the agreement on common methods and procedures and the sharing of results towards a common target (e.g., Slavin, 1990; Kose, Sahin, Ergu, \& Gezer, 2010). The promotion of the idea of effective school cooperation and partnership in meaningful activities, related to the school curriculum, is the ultimate target of the proposed large scale project. Johnson and Johnson (2009) described an effective cooperation between students as a promotion to force to reach better achievement levels compared to conventional school approaches where competitive or individualistic efforts are frequent.

Another important aspect of the success of the Eratosthenes experiment in schools is the students' engagement in an authentic experiment. One indication of engagement in learning is the time on task. Cooperators in general spend considerably more time on a task than students working individually (Johnson \& Johnson, 2009). The activity itself is usually combined with a series of hands-on activities where students were working cooperatively in the framework of meaningful activities which tend to be more involved in activities and tasks, attach greater importance to success, and engage in more on-task behavior and less apathetic, off-task, disruptive behaviors, especially when abstract geometrical problems are discussed (Johnson \& Johnson, 1999): Cooperative experiences where student are helping each other compared with competitive and individualistic ones have been found to promote more positive attitudes toward the task and the experience of working on the task.

\subsection{Demonstrate How Science Works}

Offering high school students a chance to duplicate an ancient experiment provides a large scale basis to use shadows for measuring the sun's position at noon. Comparing measurements from different latitudes permits the calculation of the Earth's circumference. However, students become aware of measurement spreads and the scientific process. Within Greece, even at a distance of $271 \mathrm{~km}$, the measurement errors summed up to $17.6 \%$, far greater than the $4.5 \%$ of Eratosthenes' original experiment. However, when using distances comparable to the original experiment, for instance the one between Athens/Pallini and Belgrade $(770 \mathrm{~km})$, similar error ranges in the calculations appear: Students see their scientific measurements equivalent to the professional ones.

Our project offers a unique opportunity to introduce students to a discussion on measurement errors and on the nature of science. Starting the discussion on the shape of the Earth, a teacher can move to the errors that are introduced at each stage of the process. The discussion could include issues related to possible errors in Eratosthenes' calculation. Different error types also reflect corresponding methodologies of science, essential for the practice of science and (in a context of scientific literacy) the analysis of its claims. Effective efforts in teaching about error could ideally be informed by earlier educational perspectives and a schema for inventorying and organizing error types. According to Allchin (2012), student-directed inquiry approaches face basic limits, whereas guided-inquiry case studies seem to function as appropriate vehicles for the introduction of scientific methodology in the classroom. On a larger scale, one may also envision a learning progression based on successively deeper understandings of error in science. Our aim for the design and implementation of the Eratosthenes experiment in school (even if some adaptation is needed: see below) is that it offers an approach to counteract a common misconception about the shape of the Earth. School children commonly hold misconceptions about the Earth's shape (American Psychological Association, see http://www.apa.org/education/k12/alternative-conceptions.aspx). Some children believe that the 
Earth is shaped like a flat rectangle or a disc that is supported by the ground and covered by the sky and solar objects above its "top" (Vosniadou, Ioannides, Dimitrakopoulou, \& Papademetriou, 2001). Due to these misconceptions, school students experience difficulty learning the correct scientific understanding of the spherical Earth taught in school. It appears that children start with an initial concept of the Earth as a physical object that has all the characteristics of physical objects in general (i.e., it is solid, stable, stationary and needing support), in which space is organized in terms of the direction of up and down and in which unsupported objects fall "down." When students are exposed to the information that the Earth is a sphere, they find it difficult to understand because it violates certain of the above-mentioned beliefs about physical objects (see, Vosniadou, 1994; Vosniadou \& Brewer, 1992; Vosniadou et al. 2001). The repetition of the Eratosthenes experiment demonstrates how in a single project all these issues connected with the nature of science and the use of the scientific methodology in the classroom can be integrated and presented to the students as a meaningful hands-on cooperative project.

\subsection{Potential Adjustments}

The Eratosthenes experiment provides a wonderful but complex activity. The focus on the effort of measuring should not neglect the processes of creating scientific knowledge. Nevertheless, some adjustments of the hands-on approach are needed since students are not familiar with trigonometry and the calculation of the angle between the stick and the sunlight is not yet known. In this case, there is a simple alternative way to measure the angle between the stick and the sunlight. By using proportional relationships (e.g. divide both sides of the triangle by 10) students draw a new triangle (by connecting the two end points) proportional to this triangle on a piece of paper. By using a goniometer, they may measure the angle between the side that represents the stick and the side that represents the stick's shadow on the triangle they drew.

Inquiry-based learning follows the steps of scientists (Krajcik, Blemenfeld, Marx, \& Soloway, 1997). Eratosthenes was one of the earlier ones who came up with an extraordinary but simple experiment and (with some luck) achieving a surprisingly accurate result. Even with today's very precise instruments, the latter isn't easy to duplicate. However, with better preconditions such as a much wider range of latitude even student measures become surprisingly accurate (error ranges of $1.3 \%$ rather than of $4.2 \%$ ). Thus, when comparing results from similar distances, $821 \mathrm{~km}$ in the case of Eratosthenes and $770 \mathrm{~km}$ within the Greece-Serbia cooperation, the first produced an error of $4.2 \%$, the latter of $3.9 \%$ ! The original experiment's accuracy is even more surprising when taking the meridian correction in mind (see Figure 4) which shortens the distance to $758 \mathrm{~km}$. Consequently, this is the science classroom to prepare future scientists!

The present work demonstrates the potential of performing a large scale educational activity in different schools in different countries with more than 2000 students actively involved in a task that is so closely connected with a measurement of their everyday experience. Nevertheless, the lack of assessment of learning outcomes is a shortcoming of the present approach. Consequently, the next approach (at the following spring in March 2015) will need to include empirical evaluation measures: Potential measures, for instance, may focus on (i) scoring of the cognitive achievement, (ii) monitoring the degree of students may realize the importance of the timing of the measurements; (iii) analyzing the agreement on common methods and procedures; (iv) sharing of results towards a common target, (v) monitoring the students' science skills, or last but not least, (vi) evaluating their satisfaction toward the experiment itself.

\section{Acknowledgements}

We thank all students and teachers involved in our study who contributed our data. Additionally, we appreciate discussion of earlier versions of the manuscript with F.-J. Scharfenberg and M.Wiseman.

\section{References}

Alberts, B. (2009). Redefining Science Education. Science, 323, 437. http://dx.doi.org/10.1126/science.1170933

Allchin, D. (2012). Teaching the Nature of Science through Scientific Error. Science Education, 96(5), 904-926. http://dx.doi.org/10.1002/sce.21019

Blanchard, M. R., Southerland, S. A., Osborne, J. W., Sampson, V. D., Annetta, L. A., \& Granger, E. M. (2010). Is inquiry possible in light of accountability? A quantitative comparison of the relative effectiveness of guided inquiry and verification laboratory instruction. Science Education, 94(4), 577-616. http://dx.doi.org/10.1002/sce.20390 
Bozic, M., \& Ducloy, M. (2008). Eratosthenes' teachings with a globe in a school yard. Physics Education, 43(2), 165-172. http://dx.doi.org/10.1088/0031-9120/43/2/005

Brooks, M. G., \& Brooks, J. G. (1999). The courage to be constructivist. Educational Leadership, 57(3), 18-24.

Bybee, R.W. (2000). Teaching science as inquiry. In van Zee, E. H. (Ed.), Inquiring into Inquiry Learning and Teaching Science (pp. 20-46). Washington, DC: AAAS.

Coleman, E. B. (1998). Using explanatory knowledge during collaborative problem-solving in science. Journal of the Learning Sciences, 7(3), 387-428. http://dx.doi.org/10.1207/s15327809j1s0703\&4_5

Dean, D., \& Kuhn, D. (2007). Direct instruction vs. discovery: The long view. Science Education, 91(3), 384-397. http://dx.doi.org/10.1002/sce.20194

Decamp, N., \& de Hosson, C. (2012). Implementing Eratosthenes' Discovery in the Classroom: Educational Difficulties Needing Attention. Science \& Education, 21(6), 911-920. http://dx.doi.org/10.1007/s11191-010-9286-3

Dutka, J. (1993). Eratosthenes' measurement of the Earth reconsidered. Archive for History of Exact Sciences, 46(1), 55-66. http://dx.doi.org/10.1007/BF00387726

Gialouri, E., Uzunoglou, M., Gargalakos, M., Sotiriou, S., \& Bogner, F.X. (2011). Teaching Real-Life Science in the Lab of Tomorrow. ASL (Advanced Science Letters), 4, 3317-3323. http://dx.doi.org/10.1166/asl.2011.2041

Ireland, J. E., Watters, J. J., Lupton, M., \& Lunn, J. M. (2014). Approaches to Inquiry Teaching: Elementary Teacher's Perspectives. International Journal of Science Education, 36(10), 1733-1750. http://dx.doi.org/10.1080/09500693.2013.877618

ISE. Inspiring Science Education. Retrieved Dec 11, 2013 from http:// http://inspiring-science-education.eu

Johnson, D.W., \& Johnson, F. (2009). Joining together: Group theory and group skills (10th ed.). Boston: Allyn \& Bacon.

Johnson, D.W., \& Johnson, R.T. (1999). Learning together and alone: Cooperative, competitive, and individualistic learning (5th ed.). Boston: Allyn \& Bacon.

Kirschner, P.A., Sweller, J., \& Clark, R.E. (2006). Why minimal guidance during instruction does not work: An analysis of the failure of constructivist, discovery, problem-based experiential and inquiry-based teaching. Educational Psychologist, 41, 75-86. http://dx.doi.org/10.1207/s15326985ep4102_1

Kose, S., Sahin, A., Ergu, A., \& Gezer, K. (2010). The effects of cooperative learning experience on eight grade students' achievement and attitude toward science. Education, 131(1), 169-180.

Krajcik, J., Blemenfeld, P., Marx, R., \& Soloway E. (1997). Instructional, curricular and technological supports for inquiry in science classrooms. In Minstrell, J., \& van Zee, E. (Ed.), Inquiring into Inquiry Learning and Teaching in Science. Washington, D.C., American Association for the Advancement of Science, p. 285-315.

Lott, G. W. (1983). The effect of inquiry teaching and advanced organizers upon student outcomes in science education. Journal of Research in Science Teaching, 20(5), 434-438. http://dx.doi.org/10.1002/tea.3660200507

Makowski, G.J., \& Strong, W.R. (1996). Sizing up Earth: A Universal Method for Applying Eratosthenes' Earth Measurement. Journal of Geography, 95(4), 174-179. http://dx.doi.org/10.1080/00221349608978719

Martin-Hansen, L. (2002). Defining inquiry: Exploring the many types of inquiry in the science classroom. The Science Teacher, 69(2), 34-37.

Novak, J. D., \& Gowin, D. B. (1984). Learning how to learn. Cambridge, England: Cambridge University Press. http://dx.doi.org/10.1017/CBO9781139173469

NRC (2000). National Research Council of America: Inquiry and the national science education standards. Washington, DC: National Academy Press.

ODS. Open Discovery Space. Retrieved Dec 11, 2013 from http://www.opendiscoveryspace.eu

OSR. Open Science Resources, Brussels. Retrieved Dec 11, 2013 from http://www.osrportal.eu/; http://www.openscienceresources.eu/

Paas, F., Renkl, A., \& Sweller, J. (2004). Cognitive load theory: Instructional implications of the interaction between information structures and cognitive architecture. Instructional Science, 32, 1-8. http://dx.doi.org/10.1023/B:TRUC.0000021806.17516.d0 
Rocard M., Csermely P., Jorde D., Lenzen D., Walberg-Henriksson H., \& Hemmo V. (2007). EC High Level Group on Science Education. Science Education Now: A Renewed Pedagogy for the Future of Europe. Brussels, Belgium.

Roth, W.M., \& Roychoudhury, A. (1993). Development of science process skills in authentic contexts. Journal of Research in Science Teaching, 30, 127-152. http://dx.doi.org/10.1002/tea.3660300203

Sampson, D.G., Zervas, P., \& Sotiriou, S. (2011). Science Education Resources supported with Educational Metadata: The Case of the OpenScienceResources Web Repository. ASL (Advanced Science Letters), 4(11/12), 3353-3361. http://dx.doi.org/10.1166/asl.2011.2045

Scharfenberg, F.-J., \& Bogner, F.X. (2010). Instructional efficiency of changing cognitive load in an out-of-school laboratory. International Journal of Science Education, 32(6), 829-844. http://dx.doi.org/10.1080/09500690902948862

Scharfenberg, F.-J., \& Bogner, F.X. (2013). Teaching gene technology in an outreach lab: Students' assigned cognitive load clusters and the clusters' relationships to learner characteristics, laboratory variables, and cognitive achievement. Research in Science Education, 43(1), 141-161. http://dx.doi.org/10.1007/s11165-011-9251-4

Slavin, R. E. (1990). Cooperative learning: Theory, research, and practice. (2nd ed.). New Jersey: Prentice Hall.

Sotiriou, S., \& Bogner, F.X. (2005). The Pathway to High Quality Science Teaching. Athens. http://dx.doi.org/10.1166/asl.2011.2039

Sotiriou, S., \& Bogner, F.X. (2011). Inspiring Science Learning: Designing the Science Classroom of the Future. ASL (Advanced Science Letters), 4, 3304-3309.

Sweller, J. (1988). Cognitive load during problem-solving: Effects on learning. Cognitive Science, 12, 257-285. http://dx.doi.org/10.1207/s15516709 cog1202_4

Van Joolingen, W.R., de Jong, T., Lazonder, W.W., Savelsbergh, E.R., \& Manlove, S. (2005). Co-Lab: Research and development of an online learning environment for collaborative scientific discovery learning. Computers in Human Behavior, 21, 671-688. http://dx.doi.org/10.1016/j.chb.2004.10.039

Vosniadou, S. (1994). Universal and Culture-Specific Properties of Children's Mental Models of the Earth. In L. Hirschfeld \& S. Gelman (eds.), Mapping the mind. New York, Cambridge University Press, pp. 412-430. http://dx.doi.org/10.1017/CBO9780511752902.017

Vosniadou, S., \& Brewer, W.F. (1992). Mental models of the earth: A study of conceptual change in childhood. Cognitive Psychology, 24, 535-585. http://dx.doi.org/10.1016/0010-0285(92)90018-W

Vosniadou, S., Ioannides, C., Dimitrakopoulou, A., \& Papademetriou, E. (2001). Designing learning environments to promote conceptual change in science. Learning and Instruction, 11, 381-419. http://dx.doi.org/10.1016/S0959-4752(00)00038-4

\section{Appendix}

The procedure is the following: (i) Open the program and on the bar on the left, (it is hidden until the mouse goes over) select the top icon "Location Window". (ii) Insert your school location (recommended) either from the list or by giving the respective coordinates. (iii) Locate the sun and click on it so that you can see its information on the top left corner of your screen. Then select the "Time/Date" Window. (iv) Set the date when the measurement is planned to take place and start changing the time while checking the value for the Sun's Azimuth. The goal is to find the time when the Azimuth is $180^{\circ}$. When you find at what time the sun's azimuth is $180^{\circ}$ write down the time. This is the time the measurement should take place at the given date for the given location. 